\title{
Laterally extended endopelvic resection with external iliac vessels resection and crossover ileofemoral bypass
}

\author{
David Cibula, ${ }^{1}$ Petr Mitáš ${ }^{2}$
}

\begin{abstract}
${ }^{1}$ Gynaecologic Oncology Center, Department of Obstetrics and Gynecology, Charles University First Faculty of Medicine, Prague, Czech Republic ${ }^{2}$ Second Surgical Clinic of Cardiovascular Surgery, Charles University First Faculty of Medicine, Prague, Czech Republic
\end{abstract}

Correspondence to Dr David Cibula, Gynaecologic Oncology Center, Department of Obstetrics and Gynecology, First Faculty of Medicine, Charles University, General University Hospital, Prague, Czech Republic; dc@davidcibula.cz

Accepted 3 June 2019 Published Online First 17 July 2019

Check for updates

(c) IGCS and ESGO 2019. № commercial re-use. See rights and permissions. Published by BMJ.

To cite: Cibula D, Mitáś $P$.

Int J Gynecol Cancer

2019;29:1338.
Involvement of major pelvic vessels is one of the traditional contraindications of surgical treatment for recurrent gynecologic cancers. In our experience, ligation of the external iliac vein is also feasible without replacement, though it does however cause transitory severe edema of the lower leg, which can result in chronic lymphedema. The external iliac artery remains an ultimate limit if it is involved in a tumor, and its resection always requires reconstruction. video 1 demonstrates a procedure that enables extension of the surgical field beyond traditional limits, with ligation of the common iliac vessels just below the aorta and vena cava bifurcations, resulting in free surgical margins.

A 58-year-old patient was diagnosed with highrisk endometrial cancer in 2014, when she rejected adjuvant radiotherapy after laparoscopically assisted vaginal hysterectomy. Lateral pelvic side wall recurrence occurred 3 years later with the involvement of the right ureter, external and internal iliac vessels, and medial part of the psoas muscle. She had no pain but suffered from a right lower leg lymphedema due to external iliac vein occlusion. The first vascular procedure was performed in April 2017: crossover arterial ileofemoral bypass from left to right and autogenous femoro-femoral crossover venous bypass. The pelvic procedure followed 4 days later: laterally extended endopelvic resection on the right side, including resection of the internal, external, and common iliac vessels; obturator vessels; and nerves and right ureter. The pathology report confirmed the infiltration of all structures by the endometrial cancer, which invaded the external iliac vein and surrounded the artery. The post-operative period was uneventful, and the patient was dismissed from the hospital on the sixth day after

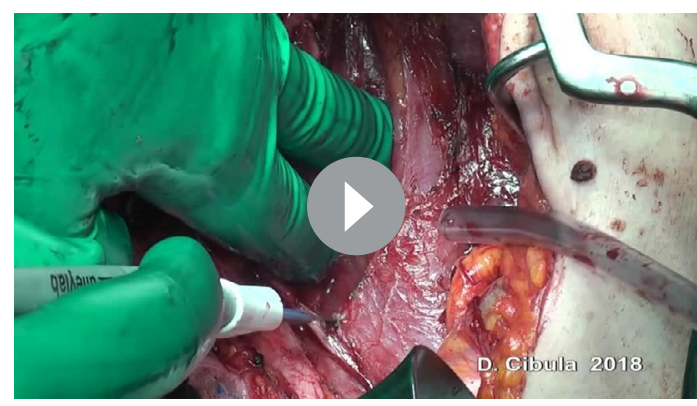

Video 1.

the second surgery. The late post-operative period was complicated by the secondary healing of the right groin with a necessity to apply a vacuum-assisted closure system. The patient reported a weak adduction of the right leg, which fully recovered after rehabilitation. The last follow-up visit was in April 2019 when the patient was asymptomatic, without any evidence of the disease. In conclusion, crossover vascular iliofemoral bypass prior to pelvic resection is a feasible solution for achieving complete resection of pelvic tumors involving external and/or common iliac vessels.

Acknowledgements This work was supported by Charles University in Prague (UNCE 204065 and PROGRES Q28/LF1)

Contributors DC: exenterative part of the surgery, video editing, commentary writing. PM: vascular part of the surgery, commentary reviewing.

Funding This study was supported by Univerzita Karlova v Praze. Competing interests None declared.

Patient consent for publication Not required.

Provenance and peer review Not commissioned; externally peer reviewed. 